\title{
Analysis on the Application of Career Anchor Theory in the Career Development Planning of Veterans
}

\author{
Lei $\mathrm{Li}^{1{ }^{1, *}}$ Jun Chu ${ }^{2}$ Xueyang Qi ${ }^{1}$ Zheng $\mathrm{Wan}^{3}$
}

${ }^{1}$ College of Information and Communication, National University of Defense Technology, Changsha, Hunan, China

${ }^{2}$ Human Resources Office, Northwest University of Politics and Law, Xi'an, Shaanxi, China

${ }^{3}$ Army Academy of Border and Coastal Defence, Xi'an, Shaanxi, China

*Corresponding author. Email: leileibaby1982@126.com

\begin{abstract}
After the "Opinions on Promoting the Employment and Entrepreneurship of Veterans in the New Era" was released, the employment of veterans has attracted more and more attention from leaders at all levels of the military and local governments. China has introduced a series of safeguard measures, but there are still many veterans who are confused about their career positioning. Career Anchor Theory can help veterans to position their careers more realistically. This paper briefly describes the characteristics of Career Anchor Theory, analyzes the problems of veterans in career planning, and puts forward the advantages of using Career Anchor Theory to help veterans in career planning.
\end{abstract}

\section{Keywords: veterans, career planning, Career Anchor Theory}

\section{INTRODUCTION}

At present, when veterans are faced with job selection and employment, there are many practical problems. The main reason is that the drastic changes in the employment environment have led to inaccurate and even misplaced self-recognition of veterans. Using Career Anchor Theory to guide veterans in career development planning can help them to accurately recognize themselves, adapt to the external environment, avoid detours when choosing careers and employment, and scientifically and accurately debug career planning goals and paths.

\section{PROBlemS OF VETERANS IN CAREER DEVELOPMENT PLANNING}

\section{A. Having no concept of career planning, and their development all depends on trial and error}

The lack of understanding of career development planning is a flaw when veterans choose a job or employment. Veterans are generally full of enthusiasm before retiring. They always think that they can do a lot when they return to the local, and finally find that there is still a certain gap between ideals and reality. When in the army, strict and regular management brings to the veterans a proactive and energetic drive, and the overall situation is the most important thing for them at all times. But after really returning to the local, facing the reality of inexperience, no education background, no way, and no idea of the surrounding situation, the enthusiasm of the veterans slowly fades away. The pressure of survival forces them to take action, do whatever it takes to earn quick money, do whatever their friends and family are doing, or throw themselves into the workplace for trial and error. They rarely have the concept of career development planning, let alone further understanding. After taking off their military uniforms, some veterans try a lot of jobs. Some are door guards and some are washing dishes, being submerged in the crowd unsuccessful. There are also people who are unable to achieve their heart's desire but unwilling to accept less, unwilling to lower their gestures and lower themselves to work in ordinary jobs. They have not gone out to look for work for several years, and have become the boomerang kids in the eyes of others. Compared with their peers, their job levels are low and their incomes are low; compared with their competitors in the workplace, they have lower education background and older age. At the same time, companies also have stereotypes about the position recognition of veterans, and most of them are provided with relatively low-tech positions such as drivers, bodyguards, and salesmen. Many veterans once sold insurance, houses, and gym cards. It is difficult for them to enter the formal career development after going round and round for a few years. Those who are lucky have entered the formal career development after one or two years, and those who are not lucky are still groping for two or three years, and their future is at a loss. This method of trial and error with no purpose and method is too costly for individuals. It will not only affect the selfconfidence of veterans, but also affect or change the career development path of veterans. What's more, it 
will bring some unfavorable factors to personal family and social stability.

\section{B. Having misunderstanding of career planning, and their development all depends on relationships}

Some veterans also have a career development plan for themselves after being discharged from the army, but because they have not received formal career development planning courses, they have a wrong understanding of career development planning. Veterans who have a long attended time are older than other newcomers in the workplace. The long-term military life makes them feel uncomfortable in returning to society. When the differences in living habits and thinking and cognition cause professional difficulties, most veterans mistakenly believe that it is caused by "no relationships", and they take it for granted that if they have relationships, they can find a stable job, such as civil servants, workers in stateowned enterprises, or a stable position in a large companies; they believe that if they don't have relationships, they have no access to "a secure job", and can only find ways on their own. When they consider where to go for development, they are not considering which profession or job they are suitable for, but first look at "where the relationship is". This kind of misunderstanding has led to the formation of waiting and dependence psychology, which makes them lack the motivation for struggle and scientific career development planning. With the rapid changes of the times, the types of occupations are also undergoing earth-shaking changes. People who pursue "relationships" and "a secure job" will complain if they develop poorly, do not reflect on their own career development planning, but blame it on finding the wrong relationships or not having relationships. In the long run, their mentality is unbalanced, and there is no way to talk about career development planning.

\section{Having no idea of how to do career planning, and their development all depends on luck}

Although some veterans understand that career development planning should be carried out, because they have not received formal professional development planning related training, they often implement career development planning according to their own understanding when facing job selection and reemployment. In this way, there are inevitably biases and shortcomings. Many veterans also have relatively clear goals when they retire, but when they connect with the real world, they "have grandiose aims but puny abilities" and will be "unrealistic". In fact, most people do not have "puny abilities", but don't know how to take the first step, let alone the second and third steps, so they are confused, wait-and-see, and impetuous. therefore. They do not have a scientific career planning method, which often leads to phenomena such as unclear self-understanding, scanty knowledge of job requirements, and unclear development paths, not to mention moving in the right direction. Therefore, in the career development planning of veterans, they must master scientific and effective methods, and only in this way can they get twice the result with half the effort.

\section{USING CAREER ANCHOR THEORY TO GUIDE VETERANS IN CAREER DEVELOPMENT PLANNING}

To use Career Anchor Theory to guide veterans in career development planning, it's necessary for them to first accurately understand the meaning of career anchor, and then master the process of applying the theory to practice to ensure the organic integration of theory and practice.

\section{A. The connotation of Career Anchor Theory}

In the current career development planning, Career Anchor Theory has become an important content and a basic concept. Career anchor is people's professional self-view. It means that when facing their future career choices and development, people are reluctant to give up the values and ideals that are convenient for positioning their careers and career pursuits. In fact, career anchor is the central basis for people when facing career choices and development.

The Career Anchor Theory was first proposed by the American occupational psychologist Professor Schein in "The Theory of Occupational Motivation" in 1978. As its name describes, just like a ship anchoring in a suitable harbor, a career anchor is a certain vital thing or value that an individual is not willing to give up in any case when he has to make a choice in the process of career development. [1] Schein believes that career development is actually a process of continuous exploration. In this process, everyone is forming a clearer career-related self-concept based on their talents, abilities, motivations, needs, attitudes and values, and eventually, a dominant career anchor will be formed. And this career anchor will play a very important role in the stability and growth path of the soldier's career, and it can also help to give play to personal strengths and obtain professional satisfaction in the profession [2].

\section{B. Using Career Anchor Theory to guide the process of career planning for veterans}

Using Career Anchor Theory to guide veterans in career planning is not just a continuation of the inherent spirit of veterans' training and scientific management of the army, it is also an important way for individuals to find positions in society that match their personal abilities and overall qualities more quickly, and to better serve the society and the country. This requires 
veterans to follow the professional development design process and carefully do each of the following links.

1) Self-evaluation: An effective career planning must be based on sufficient and correct self-knowledge and self-evaluation. Veterans must make a comprehensive and correct assessment of their interests, specialties, personality, knowledge, skills, emotional quotient, and adverse quotient to make a good career planning. To achieve accurate self-knowledge and selfevaluation, three questions must be answered: "Who am I", "What can I do", and "Where do I want to go". These three questions can be summarized into three aspects:

a) Interests: That is, What I like, what I am good at, and what I am not good at. Interest is the driving force for adults to do one thing well, and it is also the best teacher. If you do something that interests yourself, you will get twice the result with half the effort.

b) Skills: Skills, in a comprehensive view, are the comprehensive qualities and abilities of the veterans: whether the skills they are good at match the position they are applying for; whether they have the relevant vocational qualifications and constantly update the mastering skills; whether they carry out a quantitative evaluation and analysis of themselves in conjunction with the job evaluation of the work unit during their work in the army. They need to find out exactly what they like, what they can do, and what they are good at, and then find a career path that suits them best.

c) Occupational character traits: Character determines destiny, which to a large extent expresses that each different character trait will have a corresponding different path choice. Through the Big Five personality model tests, it is possible to see what kind of personality traits an individual belongs to in a more scientific way. Different personality traits are suitable for different occupations. This is understood as occupational character. For example, a crowd of high extroversion, high appropriateness, low neuroticism, and high openness belong to the extrovert and easygoing professional character. The people with personality traits of justice and emotional stability are more suitable for teamwork, can better integrate into the group, and can adapt to management positions.

2) Environmental assessment: Only by fully understanding the organizational environment, political environment and human ecological environment can veterans successfully plan for career development. Veterans must fully evaluate the impact of environmental factors on their career development, analyze the characteristics of environmental conditions, development and changes, understand the environment that is good for themselves and the environment that hinders their development, and be able to objectively grasp the advantages and avoid disadvantages in the ever-changing development, which is also a skill that should be mastered in a specific career development planning. [3] Four points should be paid attention to when conducting environmental assessment in the career planning of veterans:

As a special group, veterans have both advantages and disadvantages. Faced with different working environments, different people with different mentalities will make different decisions, which will inevitably affect the judgment of the final career planning of the veterans. During the service, the professional values and meanings of veterans are different from those of ordinary people. They not only possess the dedication and sacrifice of soldiers to the country, but also take into account the social attribute of being a social person about to enter the society. Therefore, when conducting individual career planning, they should comprehensively evaluate and strive to achieve the unity of individual and collective, individual and military, and individual and national interests. The choice of values is also a very important point for Career Anchor Theory in guiding veterans to make career development planning. For veterans, maintaining the mental state of "retiring without fading", passing on the good and fine traditional education spirit received in the army, and continuing to contribute to the society and the country are the true spirit and values of the veterans.

When making career planning, veterans should take into account the development and changes of current science and technology, and adjust their goals in a timely manner according to the direction of rapid social development, so as to cope with shifting events by sticking to a fundamental principle.

They must comprehensively measure and make overall considerations, and strive to integrate their nonmilitary career planning with their military career development, objectively and clearly analyzing the characteristics of environmental conditions, maximizing strengths and avoiding weaknesses, and giving full play to their advantages.

3) Implementation path: After the career development goals are determined at a stage, the specific implementation is the key, and how to implement it is the top priority. By taking every step steadily, the path will gradually become clear and the goal will become closer. In this process, veterans must strive to achieve "four combining and four achieving": combining the actual needs of the position, combining the reality of professional development, combining the characteristics of the position, and combining personal skills and expertise; achieving targeted learning and 
training, achieving related continuing education and training, achieving certain skills in a specific period, and achieving different goals for different tasks and different periods through working hard. The more specific and realistic the process plan, the easier it will be. During the implementation of the plan, self-check and reflection can be carried out from time to time.

4) Feedback of evaluation: The continuous changes in social development, the continuous updating of science and technology, the adjustment of national strategies, etc., will all affect the changes in social occupation types. The alterations and changes of the external environment are beyond the control of subjective factors. But if veterans want to keep up with the pace of adjustment and reform and make their career development planning successful, they need to continuously evaluate and adjust themselves. It is necessary to find the problems in each link at different stages, find out the corresponding countermeasures, adjust and improve the planning, and focus the adjustment on the unified coordination of career development and personal life goals and values.

\section{Conclusion}

Career Anchor Theory is just like a stable "boat anchor", stabilizing the career choices of veterans, clarifying their self-positioning, and guiding their active development and objective career evaluation. Regardless of whether veterans are in martial attire, career development planning is part of their life planning. They must be brave to challenge, constantly improve themselves, and make themselves more competitive, and only in this way, can they truly take the path of career development better.

\section{References}

[1] [America] E.H.Schein. Effective Management of Occupations [M]. Beijing: SDX Joint Publishing Company, 1992. (in Chinese)

[2] Li Qing, Zhou Jianxin. Introducing the Career Anchor Theory into the Career Development of Chinese Military Officers [J]. Journal of Army Military Transportation University of PLA, 2018 (2). (in Chinese)

[3] Chen Guang, Long Jie. Planning the Military Development of College Soldiers [J] Political Workers, 2010 (9). (in Chinese)

[4] Wang Jianxia, Liao Chuan. On the Theory and Application of Career Anchor Theory. Overseas Travel and Employment, 2010 (9). (in Chinese)

[5] The Effective Management of E.h.Schein. SDX Joint Publishing Company, 1992. (in Chinese)

[6] Xu Lingxiao, Zhao Jinxiu. Carrying Out Career Anchor Recognition and Constructing Career Planning for College Students [J] China Higher Education Research, 2004, (3): 80-81. (in Chinese) 